\title{
Bacteriophages as surrogates for the study of viral dispersion in open air
}

\author{
Gabriella Trombini Machado ${ }^{1}$. Claudia Ramos de Carvalho Pinto ${ }^{1}$. Luisa Andrea Villanueva da Fonseca ${ }^{1}$. \\ Taissa Cristina dos Santos Ramos ${ }^{1} \cdot$ Tuanny Fernanda Pereira Paggi $^{1} \cdot$ Beny Spira ${ }^{1}[0$
}

Received: 9 May 2021 / Revised: 9 May 2021 / Accepted: 11 May 2021 / Published online: 27 May 2021

(๑) The Author(s), under exclusive licence to Springer-Verlag GmbH Germany, part of Springer Nature 2021

\begin{abstract}
The SARS-CoV-2 pandemic has revived the debate about the routes of virus transmission and their likelihoods. It is of utmost importance to assess the risks of contamination of susceptible people by infectious individuals and to evaluate the level of SARS-CoV-2 and other respiratory viruses transmission in the community. Most countries have imposed non-pharmaceutical measures to contain SARS-CoV-2 transmission, including physical distancing and mask wearing. Here we evaluated the spreading of viruses in open air using harmless Escherichia coli bacteriophages as a surrogate. Phages were sprayed towards Petri dishes seeded with bacteria at different lengths and angles. Our results showed that the transmission rate decreased exponentially with distance. The highest recorded transmission rate was $9 \times 10^{-6} \mathrm{PFU} / \mathrm{plate}$ when phages were sprayed from a $1 \mathrm{~m}$ distance, suggesting that the probability of transmission of a single virus at a $1 \mathrm{~m}$ distance is $1: 100,000$.
\end{abstract}

Keywords Virus · Bacteriophages · Dispersion · Droplets · Open air

\section{Introduction}

The current COVID-19 pandemic has renewed the discussion about the mechanisms through which respiratory viruses, such as SARS-CoV-2 spread and contaminate susceptible people. It is widely believed that SARS-CoV-2 spreads through droplets transmitted by infected people. These droplets, often released via coughing, sneezing or by regular breathing or talking (Riediker and Tsai 2020), can be broadly classified into large ( $>5 \mu \mathrm{m}$ in diameter) and small droplets ( $\simeq 5 \mu \mathrm{m}$ in diameter) (Bar-On et al. 2020). Large droplets fall rapidly to the ground or to the nearest flat surface, while small droplets can remain airborne for an extended period of time (Wang et al. 2020). SARSCoV-2 diameter is about $100 \mathrm{~nm}$, the diameter of a droplet nuclei produced by coughing is about ten times larger, but it should be noted that expelled respiratory viruses are

Communicated by Erko Stackebrandt

Beny Spira

benys@usp.br

1 Departamento de Microbiologia, Instituto de Ciências Biomédicas, Universidade de São Paulo, São Paulo, SP, Brazil usually contained in even larger droplets (Yang et al. 2007). The mean size of droplets produced by sneezing and regular speech varies substantially and it is in the range of ten to hundreds of micrometers (Han et al. 2013). Viral transmission can occur by touching the nose or mouth mucosae with hands that have got previously in contact with surfaces contaminated by large droplets. Indeed, influenza control policies were based on the premise that most respiratory infections are transmitted by large respiratory droplets (Fennelly 2020). However, several studies have shown that humans produce infectious influenza droplets containing both aerosols (small particles) and larger droplets (Bischoff et al. 2013; Fabian et al. 2008; Lindsley et al. 2010). The situation with SARS-CoV-2 is less certain, but it seems that COVID19 propagates both via airborne and droplet transmission (Domingo et al. 2020; Morawska and Cao 2020; Tang et al. 2020; Wilson et al. 2020). While contamination by large droplets should be directly proportional to the proximity to the index subject (Brankston et al. 2007), airborne transmission which occurs via small nuclei droplets in infectious aerosols has a much further reach. In confined spaces and particularly in superspreading events, such as choir rehearsals (Hamner 2020) and prisons (Wallace 2020) small virus particles are released by infected people and accumulate in the air resulting in high transmission rates. 
During the COVID-19 pandemic governments and health agencies have been recommending or imposing different measures aiming at reducing virus transmission. Among them the requirement of physical distancing and the use of face masks. These distancing measures varied from country to country, from a recommendation to maintain 1-2 m distance among each other to strict home confinement. The 1-2 $\mathrm{m}$ distancing recommendation (WHO 2020) was based on the idea that virus transmission occurs via large droplets, as proximity to the index case was mainly associated with higher transmission (Fennelly 2020). Different countries adopted distinct approaches regarding face masks, while a few countries have not recommended mask wearing at all, others have made face masks mandatory in all public spaces, indoors and outdoors, and some only in confined spaces such as public transportation and shops. As of January 2021, only a handful of countries do not recommend the use of masks under any circumstance, while most required the use of masks at least in places where physical distancing is not possible (masks4all 2020). In the most extreme cases, mask wearing was required everywhere, even outdoors in sparsely crowded spaces, such as parks and beaches. In some countries, only certain states or provinces require the use of masks as is the case of Australia, Brazil and the United States. In the state of São Paulo in Brazil, citizens older than 3-years old are required to wear masks in all public spaces, including in open air, under the threat of heavy fines (ALESP 2020). Currently, the WHO recommends the use of face masks in settings where it is not possible to maintain a distance of at least $1 \mathrm{~m}$ from others (WHO 2020).

In principle, mask wearing by infected individuals may prevent the spread of viruses via large droplets, but only well fit respirators may offer protection from inhalation of infectious aerosols (Gawn et al. 2008). Nevertheless, randomised controlled trials in community settings have shown moderate to null protective effect of surgical masks or respirators on the transmission of respiratory viruses (Aiello et al. 2010, 2012; Bundgaard et al. 2020; Cowling et al. 2009; Larson et al. 2010; MacIntyre et al. 2009; Simmerman et al. 2011; Suess et al. 2012). Interestingly, there are no studies that evaluated the benefits of mask wearing outdoors. Here we evaluated the spreading of viruses in open air using Escherichia coli $\lambda$ bacteriophages as a surrogate for human respiratory viruses such as SARS-CoV-2 and Influenza. $\lambda$ and other bacterial phages are similar in size to SARS-CoV-2 and have been used extensively in many fields of biology research, including as models for the study of airborne and not airborne eukaryotic viruses (Black et al. 2010; Kormuth et al. 2018; Turgeon et al. 2014). In addition, they are easy to manipulate and are entirely harmless to humans and to the environment, an important pre-condition to perform experiments outside the laboratory walls. A set of experiments were conducted to test the effect of distance and movement relative to the infectious source in open settings.

\section{Material and methods}

\section{Strains and growth conditions}

E. coli strain CSH109 (ara $\Delta$ (gpt-lac)5 supE gyrA argE $E_{\text {am }}$ metB rроB) (Miller 1992) was used as a $\lambda$ Y1 phage host. Lysogeny broth (LB) and Lysogeny agar (L-agar) are the standard complex media used in this study (Miller 1992). Bacteria were grown overnight in LB medium. On the next day, $0.1 \mathrm{ml}$ of the bacterial culture were diluted in $4 \mathrm{ml}$ R-Top-agar (Miller 1992) and plated on L-agar. Bacteria were grown either in liquid or solid media at $37^{\circ} \mathrm{C}$.

\section{Phage lysate preparation}

$\lambda$ phage lysate was prepared as described (Miller 1992). Briefly, an overnight culture of strain CSH110 was diluted in LB medium and grown up to an $\mathrm{OD}_{600}$ of $0.3 .200 \mu \mathrm{l}$ of this culture were mixed with $100 \mu \mathrm{l}$ of a solution containing $10^{7}$ $\lambda \mathrm{Y} 1$ phages and $50 \mu \mathrm{l} 0.1 \mathrm{M} \mathrm{MgSO}_{4}$. The mixture was incubated in a water bath at $37^{\circ} \mathrm{C}$ for $10 \mathrm{~min} .5 \mathrm{ml} \mathrm{R}$ top-agar was then added and the mixture was poured onto an L-agar plate. The plates were incubated overnight. On the next day, the R Top-agar was scraped from the plate, which was subsequently washed with $1 \mathrm{ml} \mathrm{LB}$ medium supplemented with $0.01 \mathrm{M} \mathrm{MgSO}_{4}$ and the suspension was centrifuged at 5000 $x g$ for $20 \mathrm{~min}$. To the supernatant a 1/20 volume of chloroform was added. The lysate was stored under refrigeration until used.

Before every phage dispersion experiment the phage titer was evaluated by mixing serial dilutions of the lysate in SM solution $\left(5.8 \mathrm{~g} \mathrm{NaCl}, 2.0 \mathrm{~g} \mathrm{MgSO}_{4}, 50 \mathrm{ml}\right.$ Tris-HCl $1 \mathrm{M}$ $\mathrm{pH} 7,5$ and $0.01 \%(\mathrm{~m} / \mathrm{v})$ gelatine in $1 \mathrm{~L}$ of water) with 5 $\mathrm{ml}$ R Top-agar and $100 \mu \mathrm{l}$ of an overnight culture of strain CSH110. The mixture was poured over L-agar and the plates were incubated overnight at $37^{\circ} \mathrm{C}$. Plaques were counted to obtain the $\mathrm{PFU} / \mathrm{ml}$ concentration.

\section{Phage dispersion}

The experiments that evaluated phage dispersion were performed using a trigger sprayer (Pulverizador Uniluk 500 $\mathrm{ml}$, SP-Brazil) filled with a suspension containing a known concentration of phage $\lambda \mathrm{Y} 1$ diluted in a $0.1 \mathrm{M} \mathrm{MgSO}_{4}$. In most experiments, phage concentration in the spray bottle was $\sim 1.5 \times 10^{5} \mathrm{PFU} / \mathrm{ml}$. Each new phage dilution was tittered as described in the Phage lysate preparation section to check the actual PFU concentration. A typical spraying 
event released a range of droplet sizes with a total volume of $0.7 \mathrm{ml}$. With the exception of one experiment, all others were carried out outdoors. The spray bottle was always handled in an upright position. Plates seeded with bacteria were held at different relative positions as shown in Fig. 1 normally at 1,2 or $3 \mathrm{~m}$ away from the sprayer. The plates were kept open for $1 \mathrm{~min}$ following the spraying and then incubated overnight at $37^{\circ} \mathrm{C}$. On the next day, the plates were inspected for the presence of plaques and the PFU were counted. The outdoor phage dispersion experiments were carried out on four different occasions (9th September, 21th September, 28th September and 1st October 2020) always between 10 and $11 \mathrm{AM}$. The temperature, relative humidity and wind speed were, respectively, as follows: $24{ }^{\circ} \mathrm{C}, 61 \%$ and $8 \mathrm{Km} / \mathrm{h}$ (E) on 9th Sept.; $17^{\circ} \mathrm{C}$, $82 \%$ and $21 \mathrm{Km} / \mathrm{h}(\mathrm{S})$ on 21 th Sept.; $27^{\circ} \mathrm{C}, 40 \% ; 3 \mathrm{Km} / \mathrm{h}$ (E) on 28th Sept. and $30{ }^{\circ} \mathrm{C}, 45 \%$ and $11 \mathrm{Km} / \mathrm{h}(\mathrm{N})$ on 1st Oct. It should be noticed that the wind was partially blocked by nearby buildings. All outdoors experiments were performed in the shade so the phages or the plates were never under direct sunlight.

\section{Transmission rate calculation}

Transmission rates were computed assuming a Poisson distribution of phage plaques and by counting the number of plates containing 0 PFU in each tier (Luria and Delbruck 1943). The average number of plaques formation was calculated using the formula $\lambda=-\ln P_{0}$, where $P_{0}$ represents the ratio of plates with no plaques over the total number of plates. To obtain the transmission rate the $\lambda$ value was divided by $10^{5}$ (number of phages released by each spraying event).

\section{Droplets size measurement}

Droplet size evaluation was performed at the LAPAR, Departamento de Ciências da Produção Agrícola (UNESP - Campus de Jaboticabal) using a Laser Diffraction Particle Size Analyzer (Mastersizer $S^{\circledR}$, version 2.19) as described (Fernandes et al. 2007). The spraying was driven by a trigger pump bottle (Pulverizador Uniluk $500 \mathrm{ml}$ ) filled either with water or with a $1 \mathrm{M} \mathrm{NaCl}$ solution, positioned at 40 $\mathrm{cm}$ away from the laser beam. No significant difference between water and $\mathrm{NaCl}$ droplets was observed. Droplet samples were evaluated at $1.5 \mathrm{~s}$ while a full spray jet passed through the laser. From the information generated by the Mastersizer software, the volumetric median diameter (VMD), the coefficient of uniformity (Span) and the percentage of droplet volumes were recorded.

\section{Statistical analysis}

The standard error of the mean was calculated according to the formula SEM $=\frac{\mathrm{SD}}{\sqrt{n}}$, where SD is the standard deviation (Cumming et al. 2007). The coefficient of variation of the mean was calculated as follows: $\mathrm{CV}_{\text {mean }}=\frac{\mathrm{SEM}}{\text { mean }}$.

\section{Results}

To evaluate the pattern of virus dispersion in open air, $\lambda$ phages were sprinkled using a trigger spray bottle. Petri dishes seeded with $\lambda$-sensitive $E$. coli $\mathrm{K}$ - 12 bacteria (strain CSH110) were used to detect the presence of phages in the sprayed emissions. To establish a correlation between the distance from the phage source and the number of PFU on the plates, the phage sprayer was positioned at the same height but at increasing $10 \mathrm{~cm}$ intervals from the plate (Fig. 2B). In this experiment, the sprayer was filled with a suspension containing an average phage concentration of 3,575 PFU/ml. Each spray released $0.7 \mathrm{ml}$, i.e., 2,500 PFU. As expected, the farthest the plate from the bottle nozzle the lowest the number of plaques Fig. 2B. When sprayed from $10-30 \mathrm{~cm}$ the phage plaques formed countless aggregates on the plate lawn, but from 40 to $100 \mathrm{~cm}$ the PFU number decreased exponentially, such that only $0.15 \%$ of the phages landed on the plates when sprayed from a $100 \mathrm{~cm}$ distance. Thus the ability of the phage droplets to travel through air in a straight line decreases exponentially with distance. This experiment was conducted indoors.

To test the pattern of phage dispersion in open air, bacteria-seeded plates were placed at three different distances $(1,2$ or $3 \mathrm{~m})$ and angles $\left(0^{\circ}, 45^{\circ}\right.$ or $\left.180^{\circ}\right)$ away from the sprayer. Figure $1 \mathrm{~A}-\mathrm{C}$ illustrates the several experimental settings that were conducted, all performed in open air. With the exception of one experiment, in which the plates were positioned on the floor facing upwards (Fig. 1C), in all experimental sets the plates were handled upright (mimicking the position and angle of a human face), roughly 160 $\mathrm{cm}$ above ground and kept opened for $60 \mathrm{~s}$ following the spraying of phages. In these experiments, $\sim 10^{5} \mathrm{PFU}$ were sprayed each time from a bottled containing a phage concentration of $\sim 5 \times 10^{5} \mathrm{PFU} / \mathrm{ml}$. Overall, phage plaques were observed in 42 out of 258 plates. The PFU/plate concentration obtained in each experiment is depicted in Fig. 2A. The highest PFU count was observed in 3 plates that were placed at $1 \mathrm{~m}$ distance face up on the floor $(299,234$ and $154 \mathrm{PFU}$ ), in one plate positioned at a $1 \mathrm{~m}$ distance $45^{\circ}$ to the left (236 PFU) and in one plate placed at $1 \mathrm{~m}$ in front of the phage sprayer (93 PFU). However, even at the shortest distance $(1 \mathrm{~m})$ the majority of plates (63 out of 86 ) displayed 
Fig. 1 Experimental settings of virus spreading. A trigger sprayer containing $\sim 1.5 \cdot 10^{5}$ $\mathrm{PFU} / \mathrm{ml}$ of $\lambda$ phages was used to spray top-agar plates freshly seeded with $\sim 5 \cdot 10^{8}$ susceptible $E$. coli bacteria. Each spray ( $0.7 \mathrm{ml}$ ) contained approximately $10^{5}$ phages. A Phages were sprayed towards plates positioned at the same height but at different horizontal arrangements: Front, Back, $45^{\circ}$ to the left and $45^{\circ}$ to the right. In each situation, the plates were positioned at 1,2 or $3 \mathrm{~m}$ away from the phage source (sprayer). Plates lids were removed and the plates were held vertically for 1 min following the spray shot. B immediately following the spraying event lidless plates held vertically at 1,2 or $3 \mathrm{~m}$ from the phage source were circularly moved at walking pace either clockwise or anti-clockwise. C Phages were sprayed towards open plates at the floor at 1,2 or $3 \mathrm{~m}$ away. D Approximatelly 2,500 PFU were sprayed each time towards open plates held vertically at $10-100 \mathrm{~cm}$ away from the phage source
A

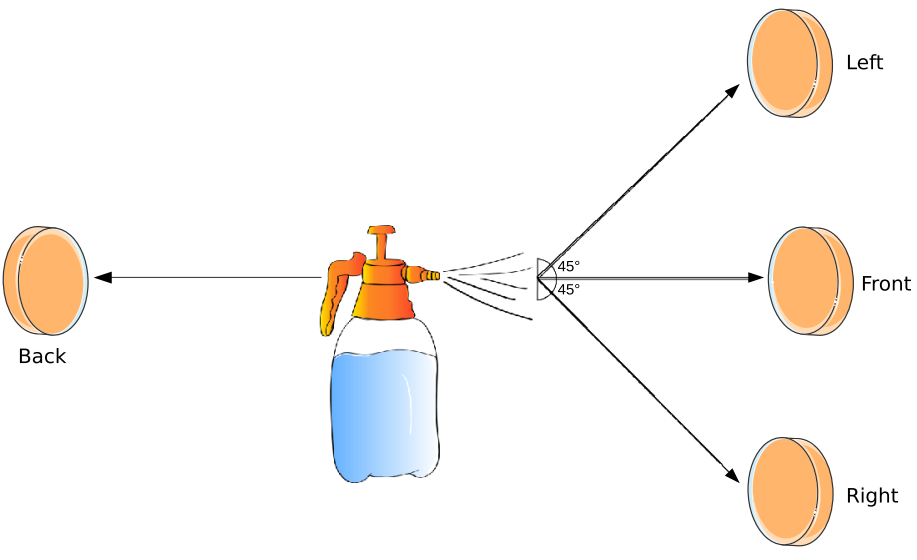

B

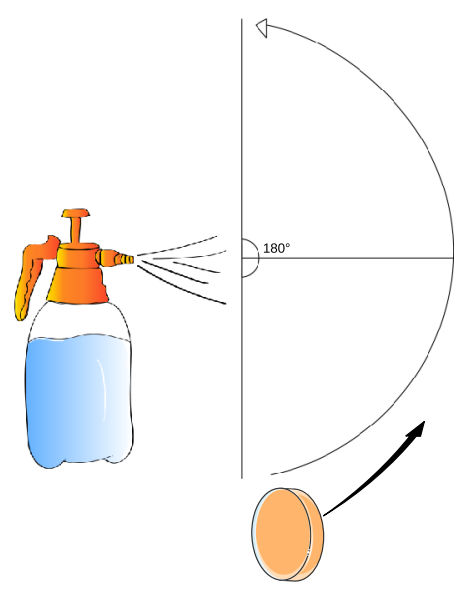

Movement

C

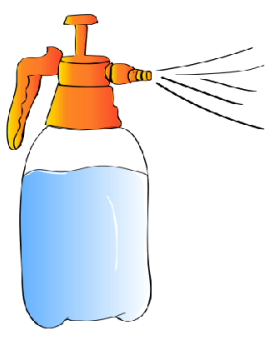

D

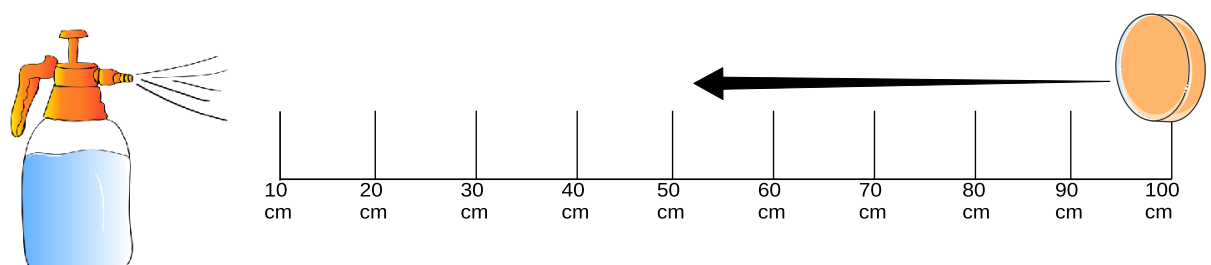


no plaques at all. Table S1 shows the PFU in each plate that did present plaques. Most plates that were placed in front of the sprayer at a $1 \mathrm{~m}$ distance ( 9 out of 12) developed at least one plaque, while $2 \mathrm{~m}$ distance, only one plate (out of 12 ) with a single plaque was observed. No plaques were found in plates distant $3 \mathrm{~m}$ from the sprayer. Under all other arrangements back, right, left, clockwise or anti-clockwise movement, only the minority of plates presented plaques and at low numbers. One exception was a plate placed at $45^{\circ}$ left at $1 \mathrm{~m}$ distance, which displayed $236 \mathrm{PFU}$. It is worth noticing that in some cases the droplets were carried by a wind gust of up to $21 \mathrm{Km} / \mathrm{h}$ blown at the precise time of spraying. The occurrence of these wind gusts might explain the high number of plaques in some plates and the presence of PFUs in plates placed at distances larger than $1 \mathrm{~m}$. In the absence of wind (most plates placed more than $1 \mathrm{~m}$ away) recorded no plaques.

Given the fact that the distribution of phages on the plates are rare positive events that occur in a continuum of space and time, the rate of transmission could be calculated by applying a Poisson distribution to the PFU results. The rate of transmission was thus computed for each experimental setting (Table 1). The highest transmission rate $-9 \times 10^{-6}$ was, as expected, observed in plates directly sprayed with phages from the short distance of $1 \mathrm{~m}$. Under the other experimental conditions the transmission rate went from 0 to $5.4 \times 10^{-6} /$ plate. In principle, the transmission rate should have been directly proportional to the distance from the phage source, but this was not always the case. For instance, spraying from a $1 \mathrm{~m}$ or $3 \mathrm{~m}$ distance in the opposite direction of the plates ('Back' in Table 1) resulted in a null transmission rate, but at a $2 \mathrm{~m}$ distance, the transmission rate was $1.7 \times 10^{-6}$. This divergence was caused by the incidence of weak wind gusts during some of the spraying events that shifted the path of the phage droplets towards or away from the plates as already pointed out.

Virus particles can be released by infected individuals through droplets having a range of sizes, from less than $1 \mu \mathrm{m}$ to more than $100 \mu \mathrm{m}$ (Han et al. 2013; Dhand and Li 2020; Riediker and Tsai 2020). To assess the size of the droplets produced by our sprayer, a laser diffraction particle size analysis was conducted. The size of the produced droplets ranged from 5 to $815 \mu \mathrm{m}$. The median size was $127 \mu \mathrm{m}$, with $50 \%$ of the droplets between 60 and $160 \mu \mathrm{m}$. Figure $2 \mathrm{C}$ show the distribution of droplet sizes discharged by the sprayer used in this study.

\section{Discussion}

In this study, we followed the spreading of phages outdoors as a surrogate for virus transmission in public open spaces. The experiment was purposely set in open air where wind and other physical conditions might have some influence on the transmission rates. At the closest distance and straight angle from the phage spreading source $(1 \mathrm{~m}$ Front in Fig. 2A) the calculated transmission rate was slightly less than $10^{-5} /$ plate, suggesting that even at this close distance (akin to an infectious individual sneezing towards a susceptible subject), the probability of getting infected with a single phage was $1: 100,000$.

Ever since the pioneer work of (Ellis and Delbrück 1939) on the infection and growth of bacterial viruses, it is known that bacteriophage adsorption to the bacterial host stops upon dilution of the bacteria:phage mixture. Namely, these authors showed that by simply diluting the phage-bacteria mixture $10,000 \times$ the infection is effectively brought to a halt. Phage dispersion in open air follows a similar dilution path, and it is even more pronounced than in liquid media because only small droplets or aerosols continue floating in the air, while large size phage-containing droplets rapidly fall to the ground. In addition, in open air the extent of dilution is orders of magnitude higher than 10,000 times. Thus, unlike a non-ventilated confined space where small virus particles accumulate in the air for an indefinite amount of time or until reaching a flat surface, in the outdoors these airborne particles simply disperse or get diluted. In addition, emitted small droplets are normally warmer than the surrounding environment and tend to move upwards getting further diluted in the air. Accordingly, it has been shown that outdoor air in residential and urban areas was mostly devoid of SARSCoV-2 particles in both northern and southern Italy during the peak of the pandemic in May 2020 (Chirizzi et al. 2020).

The amount of SARS-CoV-2 particles emitted through cough varies from 0.000277 to $36,030 / \mathrm{cm}^{3} /$ cough (Riediker and Tsai 2020). A typical virus emitter coughs $250 \mathrm{ml}$ of 0.277 virus particles $/ \mathrm{cm}^{3}$ (Riediker and Tsai 2020), i.e., 69.25 copies of virus per cough. While a single cough releases $\sim 3,000$ droplets, sneezing might produce an estimate of 40,000 droplets (Cole and Cook 1998). However, no reliable estimates of SARS-CoV-2 infectious particles released by sneezing could be found. Each phage spraying event emitted $\sim 0.7 \mathrm{ml}$, containing approximately $10^{5}$ active phages. This number is thus about 1,444 times higher than the average number of SARS-CoV-2 particles released in a single cough by a typical emitter. The precise infectious dose for SARS-CoV-2 is unknown, but it is believed to be closer to that of SARS and lower than that for MERS - requiring something between 500 and 50,000 PFU (Ryan et al. 2021). The phage dispersion experiments showed the maximal transmission rate of $9 \times 10^{-6}$, which indicates that only 1 in $\sim 100,000$ phage particles are able to reach the plate at a $1 \mathrm{~m}$ distance. At larger distances the transmission rate was even lower. In our setting a spray at a $1 \mathrm{~m}$ distance resembles a sneeze, cough or speech directed towards the face of a nearby individual. In that case, our 
A

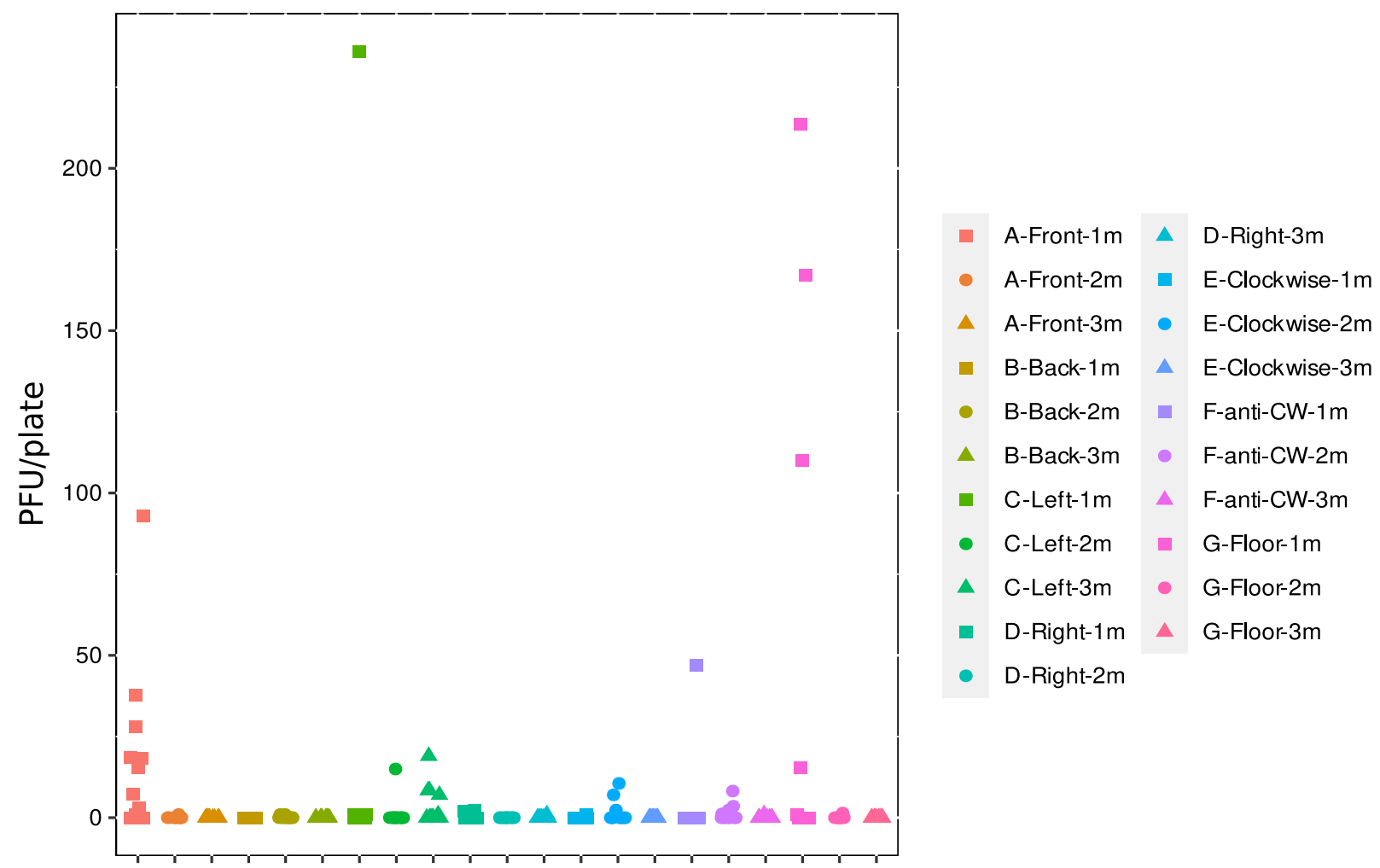

Position

B

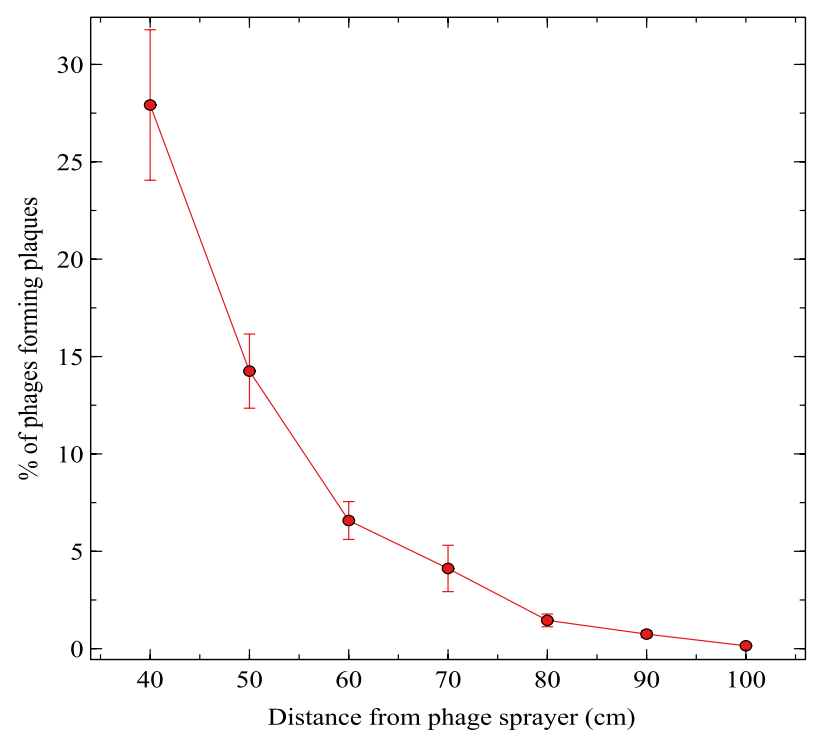

results suggest that an infectious individual coughing or sneezing should shed $10^{7}$ virus particles in order to infect a susceptible person at a $1 \mathrm{~m}$ distance with a minimal infectious dose of 100 virus particles, provided that the

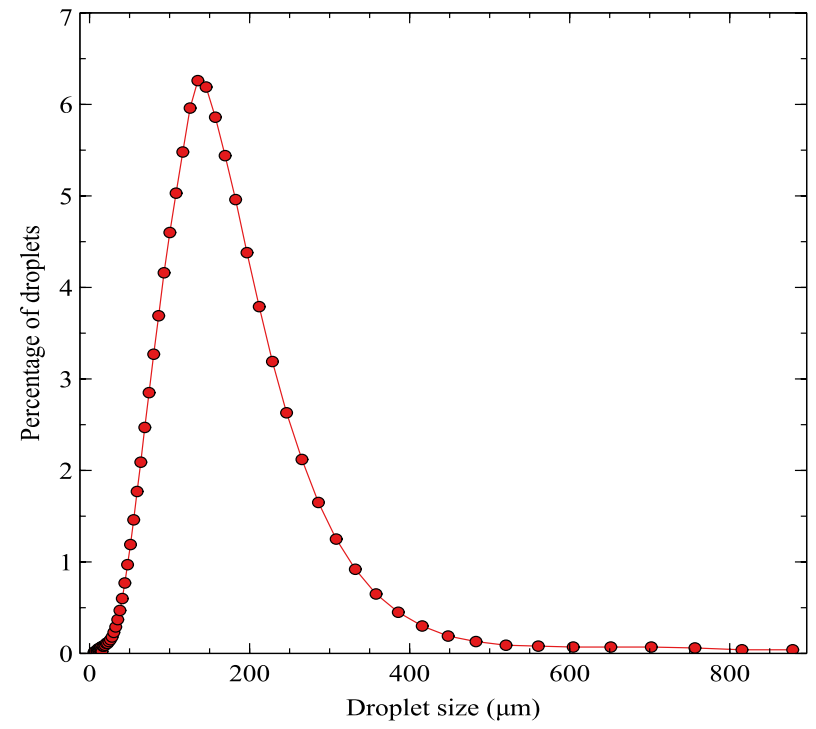

coughing/sneezing is an one-time event in open air or in an well-ventilated space.

Can SARS-CoV-2 and phage particles be compared? $\lambda$ and other bacteriophages have been used as surrogates for 
4Fig. 2 A Distribution of PFU on plates sprayed with $10^{5}$ phages. Plates freshly seeded with $E$. coli cells were sprayed with $\lambda$ phages as described in Fig. 1A-C. Each time droplets containing approximately $10^{5}$ phages were released through the nozzle of a trigger sprayer. The plates containing the bacteria were kept open for $60 \mathrm{~s}$ following the spray and incubated overnight. On the next day the phage plaques were counted. The legend at the right describes the position of the plates relative to the phage sprayer. $\mathrm{A} 1, \mathrm{~A} 2$ and $\mathrm{A} 3$ represent plates positioned at $1 \mathrm{~m}, 2 \mathrm{~m}$ and $3 \mathrm{~m}$ in front of the sprayer, respectively; $\mathrm{B} 1, \mathrm{~B} 2$ and B3 represent plates positioned at the rear of the sprayer (at a $180^{\circ}$ angle); $\mathrm{C} 1, \mathrm{C} 2$ and $\mathrm{C} 3$ represent plates positioned at the left with a $45^{\circ}$ angle from the sprayer nozzle; D1, D2 and D3 is as above except that the plates were positioned at the right; E1, E2 and E3 represent plates moving from one side of the sprayer to the other making a $180^{\circ}$ arch in a clockwise direction; F1, F2 and F3 is the same as above except that the plates were moved in an anticlockwise direction. Finally, G1, G2 and G3 represent plates placed on the floor face up. With the exception of the G1, G2 and G3 setting, in all other experiments the plates were kept open in an upright position. In all cases, 1, 2 and 3 respectively represent $1 \mathrm{~m}, 2 \mathrm{~m}$ and $3 \mathrm{~m}$ distance between the sprayer and the open plate. B. PFU number in plates exposed to phage spraying at a $40-100 \mathrm{~cm}$ range. $\lambda$ phages were sprayed towards plates seeded with $E$. coli from a spray bottle containing an average of $3,575 \mathrm{PFU} / \mathrm{ml}$. The plates were positioned in front of the bottle nozzle 40-100 cm distance, as shown in Fig. 1D. Each point represents the mean \pm S.E.M. of at least 5 independent experiments. C. Distribution of droplets size emitted by the trigger sprayer. The size of the droplets emitted by a single discharge was assessed by a laser diffraction particle size analysis

Table 1 Transmission rates in each experimental setting

\begin{tabular}{llll}
\hline Position & Transmission rate & Position & Transmission rate \\
\hline Front-1m & $9 \times 10^{-6}$ & Left-1m & $4.0 \times 10^{-6}$ \\
Front-2m & $8.7 \times 10^{-7}$ & Left-2m & $8.0 \times 10^{-7}$ \\
Front-3m & 0 & Left-3m & $4.4 \times 10^{-6}$ \\
Back-1m & 0 & Right-1m & $2.9 \times 10^{-6}$ \\
Back-2m & $1.7 \times 10^{-6}$ & Right-2m & 0 \\
Back-3m & 0 & Right-3m & $8.7 \times 10^{-7}$ \\
CW-1m & $8.7 \times 10^{-7}$ & anti-CW-1m & $8.7 \times 10^{-7}$ \\
CW-2m & $2.9 \times 10^{-6}$ & anti-CW-2m & $4.0 \times 10^{-7}$ \\
CW-3m & 0 & anti-CW-3m & $8.7 \times 10^{-7}$ \\
Floor-1m & $5.4 \times 10^{-6}$ & & \\
Floor-2m & $8.7 \times 10^{-7}$ & & \\
Floor-3m & 0 & & \\
\hline
\end{tabular}

eukaryotic viruses in many instances (Black et al. 2010; Chen et al. 2004; Kormuth et al. 2018; Yang et al. 2011; Turgeon et al. 2014). In terms of size, the circular SARS$\mathrm{CoV}-2$ has a diameter of $100 \mathrm{~nm}$, while the $\lambda$ phage has an icosahedral head with about $60 \mathrm{~nm}$ in diameter, and a non-contractile tail with about $150 \mathrm{~nm}$ in length (Furth et al. 1983; Hendrix and Casjens 2005). Given their similar dimensions both types of particles should be contained in similar droplet sizes (small and large) and follow thus comparable spreading paths. The median diameter size of the droplets produced by our sprayer was $127 \mu \mathrm{m}$, which is compatible with sneeze and speech droplets size but larger than that of cough particles (Han et al. 2013). A droplet diameter of $127 \mu \mathrm{m}$ corresponds to a volume of $0.001 \mu \mathrm{l}$. Given that the phage concentration in the sprinkler was 150,000 phages $/ \mathrm{ml}$, each droplet should carry about 0.15 phages, i.e., roughly only 1 in every 6 droplets contained a phage particle. We can therefore be confident that each observed plaque on the plates derives from a single phage.

The reported size of the droplets produced by human respiratory activities is inconsistent (Han et al. 2013; Fabian et al. 2008; Yang et al. 2007; Buckland and Tyrrel 1964). Nevertheless, the diameter of droplets produced by cough tend to be smaller than the ones produced by our sprayer. Aerosols, in particular, consist of very small particles $(<5 \mu \mathrm{m})$ that can in the absence of air currents or ventilation remain airborne for extended periods of time (Fennelly 2020). However, in open air, these small droplets tend to dilute immediately as already pointed out. The ones that may be the cause of concern in the open air are the high-velocity larger droplets produced by sneeze and those emitted by regular speech. Here we showed that this type of infectious droplets are able to infect an open Petri dish with a $9 \mathrm{~cm}$ diameter $\left(\operatorname{area}=64 \mathrm{~cm}^{2}\right)$ at a 1 $\mathrm{m}$ distance at the low rate of $10^{-5}$. At a $2 \mathrm{~m}$ distance the transmission rate drops even further. It should be noticed that the exposed area in a Petri dish is considerably larger than the total mucosal area in a human face.

In conclusion, we presented here a simplified test for the dispersion of viruses in open air. For obvious reasons, such an experiment could not be performed with live human viruses outside the laboratory, but by using a bacterial virus that is completely innocuous to all living beings, except for a narrow range of $E$. coli strains, harmless to the environment and that resembles in size respiratory viruses it was possible to evaluate the pattern of outdoors transmission. Our results suggest that virus transmission at a 1 $\mathrm{m}$ distance, i.e. not very crowded open air settings, such as streets and parks or in well-ventilated sites has a very small likelihood. Therefore, the use of face masks or any other protective shield outdoors is not required as long as a minimal distance of $1 \mathrm{~m}$ is kept among each other, as already recommended by the WHO and adopted by many countries (WHO 2020; masks4all 2020).

Supplementary Information The online version contains supplementary material available at https://doi.org/10.1007/s00203-021-02382-8.

Acknowledgements We are grateful to Fundação de Amparo à Pesquisa do Estado de São Paulo (FAPESP). B.S. is a recipient of a productivity scholarship from the Conselho Nacional de Desenvolvimento Científico e Tecnológico (CNPq). G.T.M. received a CNPq masters 
scholarship. C.R.C.P, L.A.V.F. T.C.S.R. and T.F.P.P. are recipients of CAPES graduate scholarships. The authors thank Dr. Marcelo da Costa Ferreira for kindly performing the analysis of droplets size.

Funding We are grateful to Fundação de Amparo à Pesquisa do Estado de São Paulo (FAPESP). B.S. is a Conselho Nacional de Desenvolvimento Científico e Tecnológico $(\mathrm{CNPq})$ research fellow. G.T.M. received a CNPq masters scholarship. C.R.C.P, L.A.V.F. T.C.S.R. and T.F.P.P. are recipients of Coordenação de Aperfeicoamento de Pessoal de Nível Superior (CAPES) graduate scholarships.

Availability of data and material All data is contained in the manuscript and supplement

Code availability Not applicable.

\section{Declarations}

Conflict of interest None of the authors have any conflict of interest relating to this paper.

\section{References}

Aiello AE, Murray GF, Perez V, Coulborn RM, Davis BM, Uddin M et al (2010) Mask use, hand hygiene, and seasonal influenza-like illness among young adults: a randomized intervention trial. J Infect Dis 201:491-498

Aiello AE, Perez V, Coulborn RM, Davis BM, Uddin M, Monto AS (2012) Facemasks, hand hygiene, and influenza among young adults: a randomized intervention trial. PLoS One 7:e29744

ALESP (2020) Dispõe sobre o uso geral e obrigatório de máscaras de proteção facial no contexto da pandemia da COVID-19 e dá medidas correlatas. ALESP, Sao Paulo

Bar-On YM, Flamholz A, Phillips R, Milo R (2020) SARS-CoV-2 (COVID-19) by the numbers. eLife 9:e57309

Bischoff WE, Swett K, Leng I, Peters TR (2013) Exposure to influenza virus aerosols during routine patient care. J Infect Dis 207:1037-1046

Black E, Cascarino J, Guan D, Kniel K, Hicks D, Pivarnik L et al (2010) Coliphage as pressure surrogates for enteric viruses in foods. Innov Food Sci Emerg Technol 11(2):239-244

Brankston G, Gitterman L, Hirji Z, Lemieux C, Gardam M (2007) Transmission of influenza A in human beings. Lancet Infect Dis 7:257-265

Buckland FE, Tyrrel DA (1964) Experiments on the spread of colds. 1. Laboratory studies on the dispersal of nasal secretion. J Hyg 62:365-377

Bundgaard H, Bundgaard JS, Raaschou-Pedersen DET, von Buchwald C, Todsen T, Norsk JB et al (2020) Effectiveness of adding a mask recommendation to other public health measures to prevent SARS-CoV-2 infection in Danish mask wearers: a randomized controlled trial. Ann Int Med 174(3):335-343

Chen H, Joerger RD, Kingsley DH, Hoover DG (2004) Pressure inactivation kinetics of phage \$llambda \$ CI 857. J Food Prot 67(3):505-511

Chirizzi D, Conte M, Feltracco M, Dinoi A, Gregoris E, Barbaro E et al (2020) SARS-CoV-2 concentrations and virus-laden aerosol size distributions in outdoor air in north and south of Italy. Environ Int 146:106255

Cole EC, Cook CE (1998) Characterization of infectious aerosols in health care facilities: an aid to effective engineering controls and preventive strategies. Am J Infect Cont 26:453-464
Cowling BJ, Chan KH, Fang VJ, Cheng CKY, Fung ROP, Wai W et al (2009) Facemasks and hand hygiene to prevent influenza transmission in households: a cluster randomized trial. Ann Int Med 151:437-446

Cumming G, Fidler F, Vaux D (2007) Error bars in experimental biology. J Cell Biol 177(1):7-11

Dhand R, Li J (2020) Coughs and sneezes: their role in transmission of respiratory viral infections, including SARS-CoV-2. Am J Resp Crit Care 202:651-659

Domingo JL, Marquès M, Rovira J (2020) Influence of airborne transmission of SARS-CoV-2 on COVID-19 pandemic. A review. Environ Res 188:109861

Ellis EL, Delbrück M (1939) The growth of bacteriophage. J Gen Physiol 22:365-384

Fabian P, McDevitt JJ, DeHaan WH, Fung ROP, Cowling BJ, Chan $\mathrm{KH}$ et al (2008) Influenza virus in human exhaled breath: an observational study. PLoS One 3:e2691

Fennelly KP (2020) Particle sizes of infectious aerosols: implications for infection control. Lancet Resp Med 8:914-924

Fernandes AP, Parreira RS, Ferreira MC, Romani GN (2007) Caracterização do perfil de deposição e do diâmetro de gotas e otimização do espaçamento entre bicos na barra de pulverização. Engenharia Agrícola 27(3):728-733

Furth M, Wickner S, Hendrix R, Roberts J, Stahl F, Weisberg R (1983) Lambda II. Cold Spring Harbor Laboratory Cold Spring Harbor, New York

Gawn J, Clayton M, Makison C, Crook B (2008) Evaluating the protection afforded by surgical masks against influenza bioaerosols: gross protection of surgical masks compared to filtering facepiece respirators. Health Saf Exec. https://www.hse.gov.uk/ research/rrhtm/rr619.htm

Hamner L (2020) High SARS-CoV-2 attack rate following exposure at a choir practice-Skagit County, Washington, March 2020. MMWR Morbidity and Mortality Weekly Report 69

Han ZY, Weng WG, Huang QY (2013) Characterizations of particle size distribution of the droplets exhaled by sneeze. J R Soc Interface 10:20130560

Hendrix R, Casjens S (2005) Bacteriophage \$lambda \$ and its genetic neighborhood. In: Calendar R (ed) The bacteriophages, vol 2. Oxford University Press, New York, pp 409-447

Kormuth KA, Lin K, Prussin AJ, Vejerano EP, Tiwari AJ, Cox SS et al (2018) Influenza virus infectivity is retained in aerosols and droplets independent of relative humidity. J Infect Dis 218(5):739-747

Larson EL, Ferng YH, Wong-McLoughlin J, Wang S, Haber M, Morse SS (2010) Impact of non-pharmaceutical interventions on URIs and influenza in crowded, urban households. Public Health Rep 125:178-191

Lindsley WG, Blachere FM, Thewlis RE, Vishnu A, Davis KA, Cao G et al (2010) Measurements of airborne influenza virus in aerosol particles from human coughs. PLoS One 5:e15100

Luria S, Delbruck M (1943) Mutations of bacteria from virus sensitivity to virus resistance. Genetics 28(6):491-511

MacIntyre CR, Cauchemez S, Dwyer DE, Seale H, Cheung P, Browne $\mathrm{G}$ et al (2009) Face mask use and control of respiratory virus transmission in households. Emerg Infect Dis 15:233-241

masks4all (2020) What countries require masks in public or recommend masks? https://masks4all.co/what-countries-requi re-masks-in-public/

Miller JH (1992) A short course in bacterial genetics: a laboratory manual and handbook for Escherichia coli and related bacteria. Cold Spring Harbor Laboratory, Cold Spring Harbor, New York

Morawska L, Cao J (2020) Airborne transmission of SARS-CoV-2: the world should face the reality. Environ Int 139:105730 
Riediker M, Tsai DH (2020) Estimation of Viral Aerosol Emissions From Simulated Individuals With Asymptomatic To Moderate Coronavirus disease 2019. JAMA Netw Open 3:e2013807

Ryan KA, Bewley KR, Fotheringham SA, Slack GS, Brown P, Hall Y et al (2021) Dose-dependent response to infection with SARS$\mathrm{CoV}-2$ in the ferret model and evidence of protective immunity. Nat Commun 12(1):1-13

Simmerman JM, Suntarattiwong P, Levy J, Jarman RG, Kaewchana S, Gibbons RV et al (2011) Findings from a household randomized controlled trial of hand washing and face masks to reduce influenza transmission in Bangkok, Thailand. Influenza Resp Virus 5:256-267

Suess T, Remschmidt C, Schink SB, Schweiger B, Nitsche A, Schroeder K et al (2012) The role of facemasks and hand hygiene in the prevention of influenza transmission in households: results from a cluster randomised trial; Berlin, Germany, 2009-2011. BMC Infect Dis 12:26

Tang S, Mao Y, Jones RM, Tan Q, Ji JS, Li N et al (2020) Aerosol transmission of SARS-CoV-2? Evidence, prevention and control. Environ Int 144:106039
Turgeon N, Toulouse MJ, Martel B, Moineau S, Duchaine C (2014) Comparison of five bacteriophages as models for viral aerosol studies. Appl Environ Microbiol 80(14):4242-4250

Wallace M (2020) COVID-19 in correctional and detention facilitiesUnited States, February-April 2020. MMWR Morbidity and mortality weekly report 69

Wang Y, Xu G, Huang YW (2020) Modeling the load of SARS-CoV-2 virus in human expelled particles during coughing and speaking. PLOS One 15(10):e0241539

WHO (2020) Coronavirus disease (COVID-19): masks. WHO, Geneva

Wilson N, Corbett S, Tovey E (2020) Airborne transmission of covid19. Br Med J 370:m3206

Yang S, Huang YC, Luo CH, Lin YC, Huang JW, Chuang CPJ et al (2011) Inactivation efficiency of bioaerosols using carbon nanotube plasma. Clean Soil Air Water 39(3):201-205

Yang S, Lee GWM, Chen CM, Wu CC, Yu KP (2007) The size and concentration of droplets generated by coughing in human subjects. J Aerosol Med 20:484-494 